Kalpa Publications in Computing
Volume 12, 2019, Pages 105-111
Proceedings of 4th International Conference on the
Internet, Cyber Security and Information Systems 2019

\title{
The potential use of Social Media for Healthcare Advocacy in the Democratic Republic of Congo
}

\author{
Imaja Itulelo Matiyabu $^{1^{*}}$ and Patrick Ndayizigamiye ${ }^{2 \dagger}$ \\ ${ }^{1}$ University of KwaZulu-Natal, South Africa \\ ${ }^{2}$ University of Johannesburg, South Africa \\ imajaitulelo1@gmail.com,ndayizigamiyep@uj.ac.za
}

\begin{abstract}
The healthcare system in the Democratic Republic of Congo is hampered by many challenges. Some of the challenges are due to the lack of effective mechanisms to disseminate public healthcare interventions widely. Social media, on the other hand, has proved to be effective in reaching a wide audience with specifically tailored messages. In the context of healthcare, social media enables healthcare professionals to get feedback from patients on specific health issues. Such feedback enables public healthcare stakeholders to devise adequate strategies to address specific healthcare issues. In addition, social media has been often hailed for rallying various stakeholders on a specific issue. Thus, social media has often been cited as one of the media to increase accountability and transparency in the public sector. This paper depicts the role that social media could play in public healthcare in the Democratic Republic of Congo. It portrays that social media could be used as a platform to inform the public about the national health agenda, current public health interventions at the provincial and peripheral levels and to collect feedback from citizens on the quality of healthcare. Such feedback could then be used to conduct research on how to improve current healthcare interventions.
\end{abstract}

\section{Introduction}

The 21 st century is characterised by a surge in social media use. Hudson (2019) defined social media as "a series of websites and applications designed to allow people to share content quickly, efficiently and in real-time". In addition, according to Webster (2019), social media is "a form of electronic communication (such as websites for social networking and microblogging) through which users create online communities to share information, ideas, personal messages, and other content (such as videos)".

${ }^{*}$ First author

${ }^{\dagger}$ Second author and corresponding author 
According to Hendricks (2013), social media advocacy means, "talking about a particular brand or company on your personal social media channels". He highlighted that social media advocacy helps to reach many people at the same time and there is easy interaction and engagement on posts shared on social media than using other traditional media like radio and television. Today, there are many websites and applications used by social media; and all these are subject to social media advocacy. These websites and applications can allow users to reach a considerable number of people at the right time without person-to-person communication.

The concept of social media advocacy has been used for business, politics, humanitarian purposes to name a few (Sela, 2019; Rum, 2016; Yeoman, 2016). However, in developing countries, notwithstanding the surge in social media use, the use of social media advocacy for healthcare advocacy remains largely unexplored. In the specific context of the Democratic Republic of Congo (DRC), the country faces many healthcare challenges. In view of the potential of social media to reach a large audience, it is believed that such media can assist in the dissemination of healthcare messages in the country. Thus, this paper presents a proof of concept that could be used to design healthcare advocacy interventions in the DRC using social media.

\section{Types of Social Media}

There are different categories of social media and each category has its own characteristics.

Social Networks: SEOPressor (2019) defined a social network as "social media that allows users to connect and share with people who have similar interests and backgrounds". According to Foreman (2017), social networks, also called "relationship networks" allow people and organisations to connect online and share information and ideas. He added that the most known examples of these social media are Facebook, LinkedIn and Twitter as they have become hubs through which people's lives can be improved. With the spread of mobile internet, people are using social networks to read news, to share photos, videos, and help others to find employment opportunities (Foreman, 2017). Foreman (2017) highlighted that social networks have many benefits including building relationships, brand awareness, market research, employee advocacy, and other related benefits.

Bookmarking websites: Bookmarking websites allows one to save and organise links from a number of online resources and websites (SEOPressor, 2019). These websites are so useful because they allow users to tag links for future use. Foreman (2017) added that these websites are used to discover share, discuss, save trending content and media. The most popular examples are Flipboard and Pinterest. These social media can drive brand awareness, website traffic and customer engagement. Additionally, they are a source of inspiration for those who are seeking information and ideas and when they are added to other social networks, they can potentially increase brand awareness and customers' interactions (Foreman, 2017).

Media sharing networks: according to Foreman (2017), media sharing networks are used to share videos, live video and photos and the most popular examples are Snapchat, YouTube, Vimeo and Instagram. He also highlighted that media sharing networks are useful for customer engagement, brand awareness and are so important for social marketing (Foreman, 2017).

Consumer review networks: People use consumer review networks to share, review and find information about a product, services and brands, travel destination and restaurant. The most popular examples are Yelp, TripAdvisor and Zomato (Foreman, 2017).

Blog comments and forums: according to SEOPressor (2019), these are Internet sites that allow users to get involved in conversations by posting and responding to community messages. Foreman (2017) argued that these blogs and forums are used to publish, discover and comment on online content. $\mathrm{He}$ also highlighted that these can be useful to engage with costumers, building a brand and generating sales. The most popular examples are Medium, Tumblr and WordPress (Foreman, 2017). 
Social Shopping networks: these social media allow you to follow brands and assist users to make online purchases (Foreman, 2017). These sites allow users to enhance online engagement, create online awareness and sell products online. The most useful examples are Polyvore, Etsy and Fancy (Foreman, 2017).

Sharing economy networks: social media can be a useful way to advertise, buy, sell, find, share and trade products and services online. This was confirmed by Foreman (2017) who suggested that the use of social media like Airbnb, TaskRabbit and Uber can facilitate online collaboration and online advertisement, selling and buying products online and finding, sharing, trading products and services (Foreman, 2017).

Anonymous social networks: These social networks allow users to post or make comments anonymously. Some popular anonymous social networks are Ask.fm, After School and Whisper (Foreman, 2017).

Social News: Social news are websites that allow users to post news or stories (SEOPressor, 2019). These news are then ranked according to their popularity generally through other users' votes. These news are then displayed according to their popularity. Reddit is a prominent example of this kind of websites (SEOPressor, 2019).

Microblogging is a website like twitter whereby subscribers can write content and submit it on the website walls. Thus, subscribers may post links to products and services (SEOPressor, 2019).

\section{Factors that Influence the Success of A Social Media Advocacy Campaign}

According to Heavy (2017), social media allows businesses to reach a large number of potential customers with a brand awareness message. Social media campaigns are marketing campaigns carried on platforms like Twitter, Instagram, Linkedin and Facebook (Heavy, 2017). Heavy (2017) highlighted five factors that influence the success of a social media campaign:

Consistency: with social media, it is very easy to express the brand voice (Heavy, 2017). According to Heavy (2017) companies can actually connect with their target customers and increase the number of followers on social media platforms (Heavy, 2017).

Market Research: The success of a social media campaign hinges on the ability to captivate the audience. This can be achieved by doing research to understand the audience's needs and values and then devise interventions to meet the audience's expectations. A typical example is the Air BnB social media campaign called "Live There" (Heavy, 2017). Before the implementation of this campaign, the Air BnB did a research on the needs of their target audience and found that $86 \%$ of their customers used their platform because they wanted to live like the locals of the destination to which they intended to travel. Thus, the Air BnB hired professional photographers to take pictures of different destinations and then share them on their booking webpage. This assisted their customers to get better prepared when visiting foreign destinations (Heavy, 2017).

Partnership: according to Heavy (2017), partnering with another company can improve the success of a social media campaign. This was observed with a social media campaign called "Share Your Ears" where Make-A-Wish Foundation in partnership with Disney was able to increase the impact of the campaign as many social media subscribers were encouraged to engage in the campaign (Heavy, 2017).

Social Responsibility: According to Heavy (2017), most successful social media campaigns are associated with social responsibility messages. One example is portrayed through the social media campaign \#withoutshoes of a shoe company TOMS, whereby people were encouraged to spend a day without shoes for raising awareness about those who do not have shoes worldwide. This was done by endorsing a social responsibility message on their brand personality. 


\section{Use of Social Media in Healthcare}

Social Media are mostly used by healthcare professionals to improve the quality of healthcare services and to provide information to patients. According to the University of Scranton (2019), social media are used in healthcare in various ways. These include:

Sharing Information: Healthcare professionals can share information with others concerning diseases and prevention measures using social media websites. In addition, social media can be used to introduce healthcare professionals to patients and vice versa; and to provide patients with information pertaining to their sickness (University of Scranton, 2019). Furthermore, Ventola (2014) highlighted that social media facilitate communication between a healthcare professional and colleagues, participation in online communities and getting in touch with experts in a subject matter and thus, opens the path to professional networking and sharing of health-related information. Furthermore, Bentley (2018) highlighted that social media are an effective means of disseminating information when a crisis occurs. He confirmed that Twitter was actively utilised by doctors to update patients about a specific crisis. In this case, hospitals and other healthcare organisations can easily provide an update on their hospital capacity, operational capabilities and emergency room access through social media networks during natural disasters or disease outbreaks.

Training Medical Workers and Patients: Social media is also used for healthcare professional and patient's education. According to the University of Scranton (2019), social media are used within healthcare organisations to share training videos and pictures during training sessions; to engage audiences; market their facilities and display their innovative training processes. In addition, social media enables patients' access to educational resources and join virtual communities, track personal progress, participate in research, moral and financial support and promotion of patient healthcare education. Using social media, physicians can record videos, tweet and blog posts and participate in discussion forums on patient education. Furthermore, patients can use social media to connect with others and discuss issues that affect them (Ventola, 2014). In addition, Bentley (2018) mentioned that people have started using the internet for self-diagnosis and to seek help. While all the available information on social media might not always be authentic, most of it still provides awareness of healthrelated issues and encourage people to seek treatment before it is too late. Social media provides an opportunity for healthcare organisations to raise awareness about most pertinent healthcare-related issues like diabetes, cardiac diseases, allergies and geriatric medicine. Patients who are seeking healthcare can search on social media for information on doctors, hospitals and specialists availability. Former patients can provide reviews about their experiences on healthcare services they received through social media.

Improve the quality of healthcare services: To gather feedback and improve the quality of healthcare services, interactions through social media enable doctors and physicians to receive immediate responses from individuals to help them understand common reactions to medications or their side effects. Through various feedback mechanisms provided via social media websites, healthcare professionals have the opportunity to evaluate the possibility of providing additional healthcare services (University of Scranton, 2019). In addition, social media are used to enhance a healthcare organisation's visibility and allow healthcare workers to communicate with the community and patients.

Public Healthcare programs: Social media are most important in supporting the development and implementation of public healthcare programs. Social media create vast global networks that can quickly spread information and mobilise large numbers of people toward achieving specific public healthcare goals (Ventola, 2014). Some public health organisations use keywords content from Twitter and other social networks in conjunction with location-tracking technologies, to respond rapidly to disasters and to monitor the health and welfare of populations. 


\section{Designing Healthcare Interventions Through Social Media in the Democratic Republic of Congo}

The DRC's healthcare system consists of three hierarchical levels. The central level defines the national health policy and the overall national strategic vision. It consists of the cabinet of the Minister of health, the general secretary of health, central directorates, programs and specialised services. The intermediate level has the office of the Provincial Medical Inspector and the Provincial health division. At this level, there is also a provincial coordinator in charge of specialised programs. The provincial laboratories and drug distribution centres, the services and studies unit, medical and pharmaceutical units, hygiene services are also included in this level. The peripheral level is made of the central office of the health zone headed by a Medical doctor who is the head of the Zone. The peripheral level is the operational level and it is made of the healthcare centres and the General reference Hospital.

Information flow between the three levels is often hierarchical which sometimes poses delays in decision-making. In addition, the public is often not informed of the recent development in the public healthcare sector which is an impediment to the provision of healthcare services in the country. For example, the general public is often unaware of recent public healthcare interventions.

The use of social media to enhance information flow amongst public healthcare stakeholders should take into account the role of each stakeholder in the DRC healthcare ecosystem. Social media could assist the central level, which defines the national health policy, to communicate the national healthcare agenda and new developments and progress toward the set national healthcare goals. This will enhance stakeholders' participation as the public and other stakeholders could suggest paths toward realising the set national goals. It will also increase transparency and accountability as every stakeholder could check the government progress towards achieving the goals.

The intermediate level devises healthcare interventions at the provincial level based on the directives from the national level. Such interventions could be made public through social media. This will help to track whether healthcare interventions at the provincial level are in accord with the national agenda. Recipients of these healthcare interventions may also provide feedback through social media on the quality of the healthcare services provided.

The peripheral level, which is made of healthcare centres and the general reference hospital, is the first point of public healthcare access for most of the DRC's citizens. At this level, citizens' feedback on the healthcare services they receive could help identify flaws within the entire healthcare service delivery process, that is, from the central level to the peripheral level.

Data analytics have made it possible to analyse social media content. In this case, social media content especially feedback from recipients of healthcare services could be analysed through various research designs and methods in order to suggest better ways of providing healthcare interventions. In this case, the analysis could be used by the central level to formulate new strategies or enhance the existing ones in the quest to enhance public healthcare service delivery in the DRC. below.

The potential use of social media for public healthcare advocacy in the DRC is depicted in figure 1 


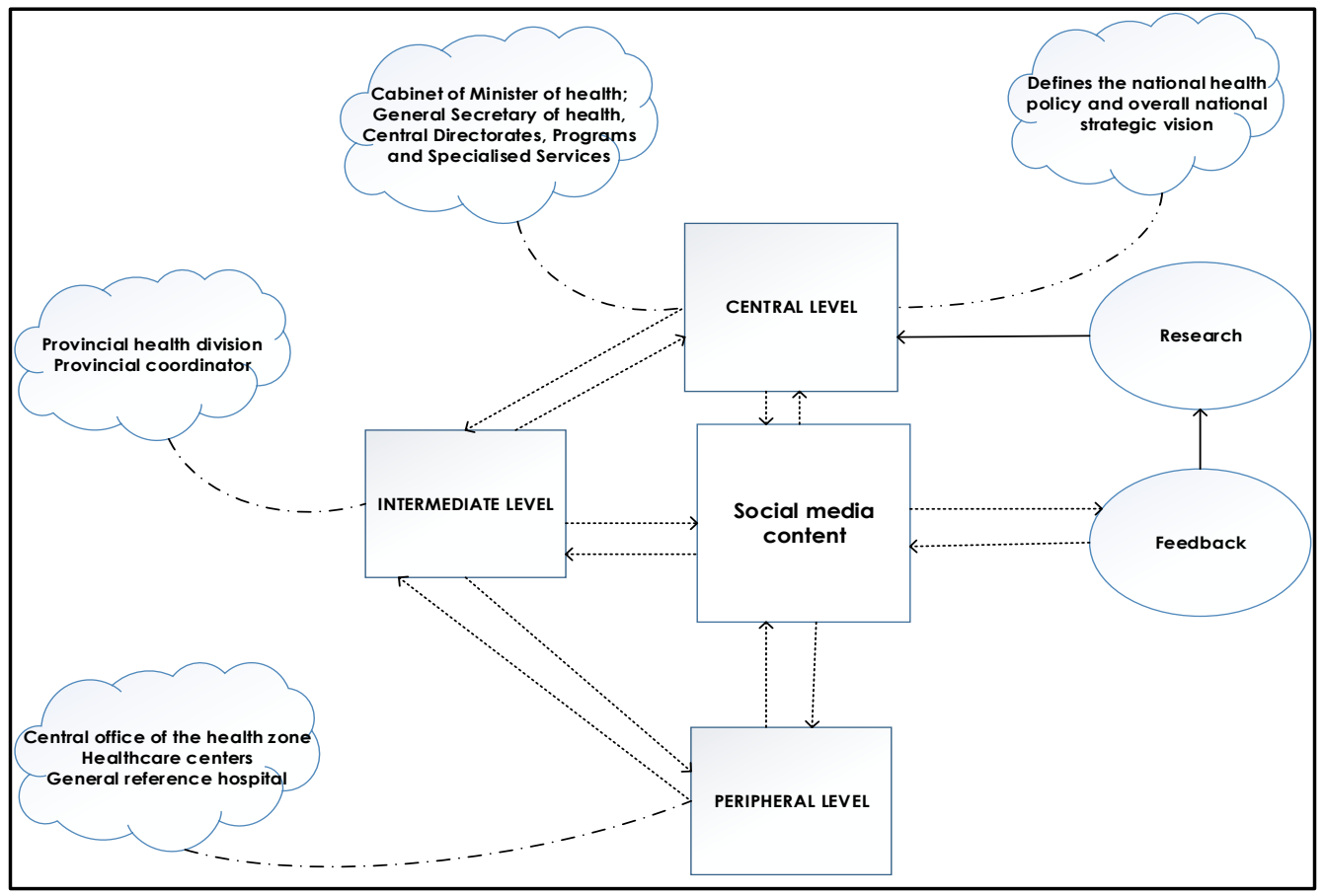

Figure 1: Potential use of social media for healthcare advocacy in the Democratic Republic of Congo

\section{Conclusion and Recommendations}

This paper portrayed various ways social media could be used to support advocacy programs. In the healthcare sector, social media could be used to share information between healthcare professionals and patients; train healthcare workers and educate patients and the general public and improve the quality of healthcare services. In the context of the DRC, the hierarchical nature of the public healthcare system and the inherent systemic issues hamper the effective provision of healthcare services in the country. Thus, social media could be used as a platform to inform the public about healthcare interventions and increase transparency and accountability within the public healthcare system in DRC.

However, for the use of social media for healthcare advocacy to be effective, there is a need for the DRC's central level to be committed toward improving transparency and accountability within the healthcare sector. In addition, there is a need to sensitize the population of the potential use of social media and assess their accessibility to the Internet, mobile devices and the literacy rate. In addition, there is a need to stimulate healthcare-related research that investigates the use of social media as a potential avenue for enhancing public healthcare service delivery in the DRC. 


\section{References}

Bentley, A. (2018). 5 Benefits of Social Media in Healthcare. Retrieved March 15, 2019, from The Healthcare guys: https://www.healthcareguys.com/2018/03/13/5-benefits-of-social-media-inhealthcare/

Foreman, C. (2017). 10 Types of Social Media and How Each Can Benefit Your Business. Retrieved May 16, 2018, from Hoot Suite: https://blog.hootsuite.com/types-of-social-media/

Heavy, D. (2017). Examples of Successful Social Media Campaigns. Retrieved January 16, 2019, from ThriveHive: https://thrivehive.com/examples-social-media-campaigns/

Hendricks, D. (2013). Complete History of Social Media: Then And Now. Retrieved January 16, 2019, from Small Business Trends: https://smallbiztrends.com/2013/05/the-complete-history-ofsocial-media-infographic.html

Hudson, M. (2019). What is Social Media? Retrieved June 21, 2018, from The balance small business: https://www.thebalancesmb.com/what-is-social-media-2890301

Rouse, M. (2019). social media. Retrieved July 15, 2019, from What is.com: https://whatis.techtarget.com/definition/social-media.

Rum, J. (2016). Ten Steps to Building an Effective Digital Strategy. Retrieved January 5, 2019, from Social Media today: https://www.socialmediatoday.com/marketing/10-steps-buildingeffective-digital-strategy

Sela, R. (2019). 7 Brand Advocacy Campaigns that Rocked Social Media. Retrieved January 6, 2019, from Ron Sela: https://www.ronsela.com/brand-advocacy-campaigns/

SEOPressor. (2019). Retrieved May 17, 2019, from Social Media Marketing: https://seopressor.com/social-media-marketing/

Trace, S. (2019). SourceTrace. Retrieved from Equitable treatment of farmers: Does technology help?: http://www.sourcetrace.com/equitable-treatment-farmers-technology-help/

University, S. (2019). Top 5 Ways Social Media is Used by Healthcare Professionals. Retrieved March 12, 2019, from The University of Scranton : https://elearning.scranton.edu/resource/businessleadership/top-5-ways-social-media-is-used-by-healthcare-professionals

Ventola, C. L. (2014). Social Media and Health Care Professionals: Benefits, Risks, and Best Practices. Pharmacy and Therapeutics, 39(7), 491-499.

Webster, M. (2019). social media. Retrieved November 28, 2018, from Merriam-Webster: https://www.merriam-webster.com/dictionary/social\%20media

Yeoman, M. (2016). The Best YouTube Marketing of 2016: Learn from Them in 2017. Retrieved January 06, 2019, from Rank Watch: https://blog.rankwatch.com/the-best-youtube-marketingof-2016-learn-from-them-in-2017/ 